\title{
Gas-Phase Substitution of Dichloro- and Dibromoethene by Ammonia and Amines via Radical Cations. A Kinetic Study by FT-ICR Spectrometry
}

\author{
Detlef Thölmann, Dirk Flottmann, and Hans-Friedrich Grützmacher* \\ Fakultät für Chemie der Universität Bielefeld, \\ Postfach 8640, W-4800 Bielefeld, F.R.G.
}

Received April 2, 1991

Key Words: Ion-molecule reactions / Radical cations / Substitution, nucleophilic / FT-ICR mass spectrometry / Calculations, MNDO

The gas-phase reactions of the three isomeric dichloroethene radical cations $1^{+}-3^{+\cdot}$ with $\mathrm{NH}_{3}$ and of the neutral species 1-3 and the isomeric 1,2-dibromoethenes 4 and 5 with $\mathrm{CH}_{3}$ $\mathrm{NH}_{2}^{+}$and $\left(\mathrm{CH}_{3}\right)_{2} \mathrm{NH}^{+}$, respectively, are studied by FourierTransform Ion-Cyclotron-Resonance (FT-ICR) mass spectrometry. A chloro substituent in $\mathbf{1}^{+\cdot}-3^{+\cdot}$ is replaced by $\mathrm{NH}_{3}$ in a fast reaction, yielding $\mathrm{C}_{2} \mathrm{H}_{5} \mathrm{NCl}^{+}$ions. These substitution reactions are very fast and occur nearly at the collision limit. The 1,1-dichloroethene radical cations $3^{+}$exchange successively both $\mathrm{Cl}$ substituents, yielding $\mathrm{C}_{2} \mathrm{H}_{7} \mathrm{~N}_{2}^{+}$ions and eventually cluster ions $\mathrm{N}_{2} \mathrm{H}_{7}^{+}$. Substitution takes place also by the reaction of neutral haloethenes $\mathbf{1 - 5}$ with amine radical cations, although at very different rates. The efficiencies of the reactions of $\mathrm{CH}_{3} \mathrm{HN}_{2}^{+} \cdot$ with $\mathbf{1}-\mathbf{5}$ are quite large, but those of the reactions of $\left(\mathrm{CH}_{3}\right)_{2} \mathrm{NH}^{+\cdot}$ with 1 and 2 are $<1 \%$ and reach only $\leq 10 \%$ even in the case of the bromoethenes 4 and $5.1,1-$ Dichlorethene (3) does not react at all. An addition-elimination mechanism is proposed for all these reactions, giving rise to the formation of intermediate $\beta$-distonic ammonium ions. This reaction path and the stability of the intermediates are supported by MNDO calculations. However, the intermediate $\beta$ distonic ions have to isomerize further by hydrogen shifts before the product ions are eventually formed. MNDO calculations support the assumption that the slow reactions of $\left(\mathrm{CH}_{3}\right)_{2} \mathrm{NH}^{+}$with the haloethenes are due to slow rearrangements within the initially formed distonic ions, which have to precede the loss of $\mathrm{Cl}^{\text {: }}$
Nucleophilic substitutions at $\mathrm{C}\left(\mathrm{sp}^{2}\right)$ atoms are known from the reactions of appropriately substituted aromatic and olefinic compounds. Although these reactions are slow in the absence of groups activating a reaction by the nucleophilic addition-elimination mechanism, it has been shown that a sufficiently nucleofugic leaving groups opens the reaction channel for a direct nucleophilic substitution via intermediate vinyl cations ${ }^{1)}$. Another possibility to activate an olefinic or aromatic compound for nucleophilic substitution could be transformation into a radical cation. Radical cations are electron-deficient species, and prima facie one expects a fast reaction by addition of the nucleophile $\mathrm{Nu}$ followed by the elimination of the radical $\mathrm{X}$ yielding the substitution product of appropriately substituted alkenes (Scheme 1).

Scheme 1

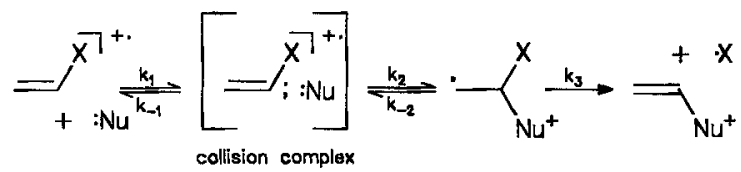

In fact, radical cations (and radical anions) have been invoked to explain certain photo-stimulated and related substitution reactions of aromatic and olefinic compounds ${ }^{2)}$. However, the detailed mechanisms of these reactions and intermediate radical cations in solution are difficult to study by conventional techniques. In contrast, charged species are easily observed and manipulated in the diluted gas phase by mass-spectrometric methods. Thus, the reac- tivity of carbocations and carbanions as well as radical ions are conveniently investigated by gas-phase ion-molecule reactions using the flowing-afterglow or SIFT technique ${ }^{3)}$ and the FourierTransform Ion-Cyclotron-Resonance (FT-ICR) method ${ }^{4)}$. By this latter technique, the ions generated by electron-impact ionization (EI) or chemical ionization (CI), respectively, are trapped at the thermal energy within an ICR cell for seconds or even minutes by a strong and homogeneous magnetic field at a background pressure of ca. $10^{-9}$ mbar. During this time the ions are allowed to react with a neutral reagent present in the cell at a known pressure of $10^{-8}-10^{-6} \mathrm{mbar}$, and the decay and the rise of the signals of the starting ions and of the ionic reaction products, respectively, with reaction time are monitored to determine the type and rate of the reaction. Additionally, the structures of the product ions can be determined separately by the usual mass-spectrometric techniques, for example by specific isotopic labeling or by collisional-activation (CA) mass spectrometry. However, one has to keep in mind certain restraints of ion-molecule reactions in the dilute gas phase. Firstly, only exothermic reactions occur at high reaction rates, because the reactions of isolated ions and molecules are observed. Secondly, the reaction between the ion and the molecule starts by the formation of an encounter complex promoted by the ion-dipole and ion-induced-dipole attraction between both reactants. Thus, the encounter complex is formed with excess energy which can be used for the chemical changes within the complex. These "intracluster" reactions may be quite complicated multi-step rearrangements before eventually a dissociation into the products takes place. The rate of a gas-phase ion-molecule reaction is most conveniently discussed by its efficiency (eff.) corresponding to the percentage of gas-phase col- 
lisions between the reactants resulting in a chemical reaction. Accordingly, the efficiency is defined by the ratio $k_{\exp } / k_{\mathrm{ADO}}$ of the bimolecular experimental rate constant $k_{\exp }$ and the ion-neutral collision rate $k_{\mathrm{ADO}}$, which can be calculated by the average dipole orientation theory (ADO theory) ${ }^{5)}$ taking into account the dipole moment $\mu$ and the polarizability $\alpha$ of the neutral reactant.

Recently, we have studied the reactions of the radical cations of a series of mono- and dihalogenated benzenes with ammonia by using FT-ICR mass spectrometry ${ }^{6}$. It had been shown earlier in a $\mathrm{CI}$ experiment ${ }^{73}$ that chlorobenzene and $\mathrm{NH}_{3}$ react by substitution in an ionized $\mathrm{NH}_{3}$ plasma. By a careful investigation of the reacting species using the FTICR technique and the isomeric dichlorobenzenes as substrates it has been shown ${ }^{8)}$ that the reaction corresponds to an ispo substitution of the chlorinated benzene radical cation by a neutral $\mathrm{NH}_{3}$ molecule. A detailed kinetic study reveals however, that the rate of the nucleophilic displacements of a halogen substituent is rather slow ${ }^{6,9)}$ in spite of the electron deficiency of the aromatic radical cations.

The efficiencies of the substitution reactions of the radical cations of mono- and dihalobenzenes are $10-15 \%$ for chloro- and bromobenzenes and decrease distinctly for iodobenzene and for the para-dihalobenzenes ${ }^{6}$. This unique behavior of the halogenated benzene radical cations in their reactions with nucleophiles is explained by the two-step addition-elimination mechanism depicted in Scheme 2. The rate-determining step of this reaction is the addition of $\mathrm{NH}_{3}$ to the radical cation. According to the Shaik-Pross model of polar reactions ${ }^{10)}$ the activation energy of the addition is controlled by the difference of the ionization energy $(I E)$ of the nucleophile and the recombination energy $(R E$, for practical purposes approximated by the $I E$ value of the corresponding neutral species) of the benzene radical cation as well as by the different electrostatic interaction of the collision complex in its relevant excited and ground state ${ }^{6)}$. It is of interest to note that similar effects on the reactivity of aromatic radical cations with $\mathrm{NH}_{3}$ have been observed independently by studying the intracluster reactions after a photoionization of halobenzene/ $\mathrm{NH}_{3}$ clusters ${ }^{11}$.

\section{Scheme 2}

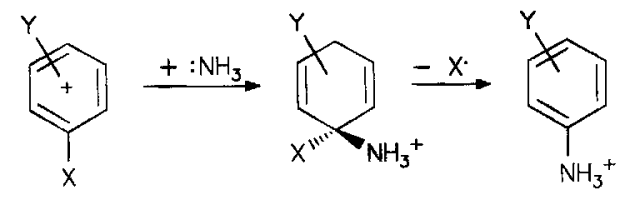

In view of the remarkable effects of the nucleophilic substitutions of radical cations of aromatic compounds it is of interest to extend the study to the reactions of olefinic radical cations. The reactivity of the radical cations of alkenes towards nucleophiles is controversial ${ }^{10 f, 12)}$, and the reactions of these radical cations both in solution and in the gas phase are probably not very well understood. Hence, we have studied the reactions of the radical cations of the isomeric dichloro- and dibromoethenes with $\mathrm{NH}_{3}$. Since the $I E$ values of these dihaloethenes are distinctly larger than those of the halobenzenes, a fast reaction is expected. A fast charge ex- change is observed during the reaction of the olefinic radical cations with methylamine and dimethylamine as a consequence of the reduced $I E$ value of the amines. However, the reaction of the radical cations of methylamine and dimethylamine, respectively, with the neutral dihaloethenes also yields substitution products, and these substitution reactions are included in our study.

\section{Results and Discussion}

\section{A) Reactions of Isomeric Dichlorethene Radical Cations with $\mathbf{N H}_{3}$}

The radical cations of $(E)$-1,2-dichlorethene $\left(1^{+}\right),(Z)-1,2-$ dichlorethene $\left(2^{+}\right)$, and 1,1-dichloroethene $\left(3^{+}\right)$were generated by $\mathrm{EI}(20 \mathrm{eV})$ in the external ion source of the FTICR instrument and transferred to the ICR cell containing $\mathrm{NH}_{3}$ at a constant pressure of ca. $10^{-7}$ mbar. All ions besides the radical cations $(m / z=96)$ of 1,2 and 3 , respectively, containing ${ }^{1} \mathrm{H},{ }^{12} \mathrm{C},{ }^{35} \mathrm{Cl}$ only, were removed from the cell, and the reactions of the radical cations $(m / z=96)$ were observed for several seconds. In all cases an exponential decay of the signal $m / z=96$ was observed, corresponding to a pseudo first-order reaction of the dichloroethene radical cations with $\mathrm{NH}_{3}$. The product ion peaks appeared at $m / z=78$ besides some ions with $m / z=18\left(\mathrm{NH}_{4}{ }^{+}\right)$. The latter ions are formed quickly within a short period at the beginning of the process by the very fast reaction $\mathrm{NH}_{3}^{+}{ }^{+}$ $\mathrm{NH}_{3} \rightarrow \mathrm{NH}_{4}^{+}+\mathrm{NH}_{2}{ }^{13}$. The $\mathrm{NH}_{3}^{+}$ions very likely arise from an endothermic charge-exchange reaction of $1^{+}, 2^{+}$, or $3^{+}$, still containing some kinetic energy from the transfer process. During the latter periods of the reaction $\mathrm{NH}_{4}^{+}$is also formed slowly by a proton transfer from the product ions of the substitution reactions to $\mathrm{NH}_{3}$. These side reactions do not interfere with the rate determination of the main process. The elemental composition of the ions with $\mathrm{m} / \mathrm{z}=$ 78 was shown by exact-mass measurement at high mass resolution ( $>100.000$ ) to correspond to ${ }^{12} \mathrm{C}_{2}{ }^{1} \mathrm{H}_{5}{ }^{14} \mathrm{~N}^{35} \mathrm{Cl}$. This confirms the substitution of one ${ }^{35} \mathrm{Cl}$ substituent of $1^{+}, 2^{+}$, and $3^{+}$, respectively, by an $\mathrm{NH}_{3}$ group. No adduct ions $\left({ }^{12} \mathrm{C}_{2}{ }^{1} \mathrm{H}_{2}{ }^{35} \mathrm{Cl}_{2} \cdot \mathrm{NH}_{3}, m / z=113\right)$ were observed, however.

In the case of $3^{+\cdot}$ the substitution product ion with $m / z=78$ reacts again with $\mathrm{NH}_{3}$ to form an ion with

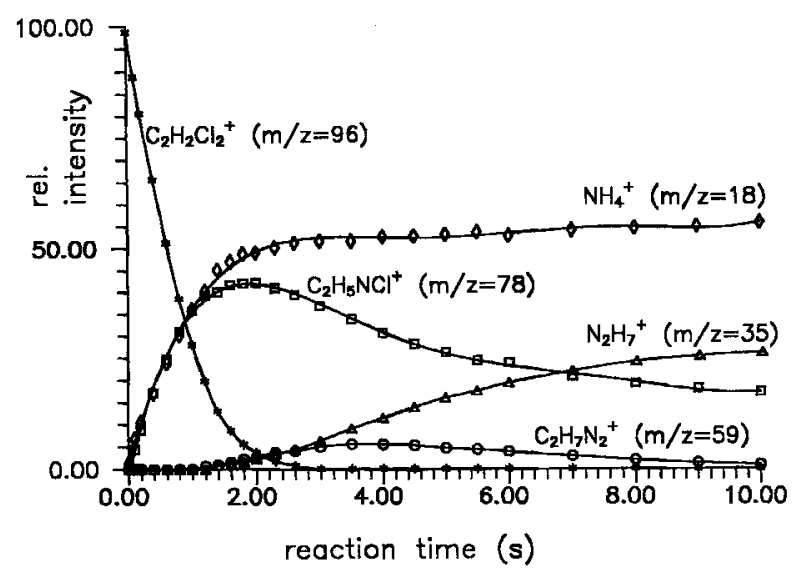

Figure 1. Reaction of 1,1-dichloroethane radical cations with $\mathrm{NH}_{3}$ at a calibrated pressure of $1.3 \cdot 10^{-7} \mathrm{mbar}$ 
$m / z=59\left({ }^{12} \mathrm{C}_{2}{ }^{1} \mathrm{H}_{7}{ }^{14} \mathrm{~N}_{2}\right)$ and eventually ions with $m / z=35$ $\left({ }^{14} \mathrm{~N}_{2}{ }^{1} \mathrm{H}_{7}\right)$; both formulas have been established by exactmass determination. This reaction sequence is clearly seen form the kinetic curves shown in Figure 1. The substitution of the first ${ }^{35} \mathrm{Cl}$ of $3^{+\cdot}$ yielding an ion with $m / z=78$ is fast while the further substitution is rather slow. The slow formation of the secondary product ion with $m / z=59$ is followed by a fast reaction yielding cluster ions $\left[\mathrm{NH}_{4}^{+} \cdot \mathrm{NH}_{3}\right]$ $(m / z=35)$, the relative abundance of ions with $m / z=59$ remaining small throughout the reaction.

The bimolecular rate constants $k_{\text {exp }}$ of the substitution of the dichlorethene radical cations were obtained from the pseudo-first-order rate constants by taking into account the concentration of $\mathrm{NH}_{3}$ in the ICR cell, and the values of $k_{\text {exp }}$ are listed in Table 1 together with some thermochemical data of the reactions. The experimental limits of error are estimated to be $\pm 20 \%$, the variation of measurements at different pressures is less than $10 \%$. The heats of formation $\left(\Delta H_{f}\right)$ of 1,2 and 3 and of their radical cations are known ${ }^{14)}$ but not the $\Delta H_{\mathrm{f}}$ values of the product ions. The latter were calculated for different product-ion structures by $\mathrm{MNDO}^{15}$. It is known that $\Delta H_{\mathrm{f}}$ values obtained by MNDO may deviate systematically from the experimental data by ca. 40

Table 1. Rate constants $k$, efficiencis (eff.), and energetics ${ }^{\text {a) }}$ of the reactions of dichloroethene radical cations $1^{+\cdot}-3^{++}$with $\mathrm{NH}_{3}$

\begin{tabular}{|c|c|c|c|c|c|}
\hline $\begin{array}{l}\text { Radical } \\
\text { cation }\end{array}$ & $k^{b)}$ & eff. c) & $\begin{array}{c}\text { Formation } \\
\text { of b/b' } \\
\Delta \mathbf{H}_{\mathbf{r}} \\
{\left[\mathrm{kJ} \mathrm{mol}^{-1}\right]}\end{array}$ & $\begin{array}{c}\text { Formation } \\
\text { of } \mathbf{c} / \mathbf{c}^{\prime} \\
\Delta \mathbf{H}_{\mathbf{r}} \\
{\left[\mathrm{kJ} \mathrm{mol}^{-1}\right]}\end{array}$ & $\begin{array}{c}\text { Enthalpy of } \\
\text { addition } \\
\Delta \mathbf{H}_{\mathrm{add}} \\
{\left[\mathrm{kJ} \mathrm{mol}^{-1}\right]}\end{array}$ \\
\hline $1^{+\cdot}$ & $8.5 \cdot 10^{-10}$ & $50 \%$ & -49 & -80 & -160 \\
\hline $2^{+\cdot}$ & $8.4 \cdot 10^{-10}$ & $50 \%$ & -50 & -81 & -161 \\
\hline $3^{+\cdot}$ & $9.2 \cdot 10^{-10}$ & $54 \%$ & -53 & -98 & $-132^{d)}$ \\
\hline
\end{tabular}

a) Heats of reaction/formation $\Delta H_{\mathrm{r}} / \Delta H_{\mathrm{f}}$ according to MNDO calculations. - b) In units $\left[\mathrm{cm}^{3}\right.$ molecule $\left.{ }^{-1} \mathrm{~s}^{-1}\right]$. - collision rate according to the ADO theory. - ${ }^{\text {d) }}$ Formation of a": $\Delta H_{\text {add }}=$ $-198 \mathrm{~kJ} \mathrm{~mol}^{-1}$.

Table 2. Experimental and calculated heats of formation $\Delta H_{\mathrm{I}}$ of radical cations $1^{+\cdot}-3^{+\cdot}$ and reactions products with $\mathrm{NH}_{3}{ }^{\text {a) }}$

\begin{tabular}{|c|c|c|}
\hline Compound & $\begin{array}{c}\text { MNDO Calculations } \\
\Delta \mathrm{H}_{\mathrm{f}}\left[\mathrm{kJ} \mathrm{mol}^{-1}\right]\end{array}$ & 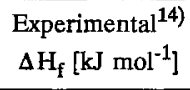 \\
\hline $1^{+\cdot}$ & 947 & 937 \\
\hline $2^{+\cdot}$ & 948 & 937 \\
\hline $3^{+\cdot}$ & 964 & 946 \\
\hline $\mathbf{a}$ & 761 & \\
\hline$a^{\prime}$ & 806 & \\
\hline$a "$ & 746 & \\
\hline b & 751 & \\
\hline b' & 764 & \\
\hline c & 720 & \\
\hline $\mathbf{c}^{\prime}$ & 719 & \\
\hline $\mathrm{NH}_{3}$ & -26 & -46 \\
\hline $\mathrm{Cl}^{\circ}$ & 121 & 120 \\
\hline
\end{tabular}

a) For structure of ions see Schemes 3 and 4 .
$\mathrm{kJ} / \mathrm{mol}^{16)}$. Therefore, the $\Delta H_{\mathrm{f}}$ values of all species of a specific reaction were calculated by MNDO to compensate for the systematic errors (Table 2), and these values were used to estimate the enthalpy of the total reaction and individual reaction steps.

The reactions of $1^{+\cdot}-3^{+\cdot}$ with $\mathrm{NH}_{3}$ are most easily explained by an addition-elimination mechanism depicted in a general form in Scheme 1 and more specifically in Schemes 3 and 4 . The structure of the product ions with $m / z=78$ may correspond to a protonated enamine $\mathbf{b}\left(\mathbf{b}^{\prime}\right)$ or more likely to a more stable immonium ion $\mathbf{c}\left(\mathbf{c}^{\prime}\right)$. In both cases the total reaction is exothermic, and it is not possible to determine the product-ion structures unequivocally. Furthermore, it may be that ions $\mathbf{c}\left(\mathbf{c}^{\prime}\right)$ are formed by isomerization of $\mathbf{b}\left(\mathbf{b}^{\prime}\right)$ after the substitution (however, see Part $\mathbf{B}$ ). The addition of $\mathrm{NH}_{3}$ to $1^{+\cdot}$ and $\mathbf{2}^{+\cdot}$ in the collision complex results in the distonic ion ${ }^{17)}$ a (Scheme 3 ) irrespective of the $\mathrm{C}$ atom attacked and the stereochemistry of the radical cation. This addition step is exothermic by ca. $160 \mathrm{~kJ} / \mathrm{mol}$ (Table 1), and $a$ is formed as a strongly chemically activated species. The elimination of $\mathrm{Cl}^{-}$from a completes the reaction, and the final collision complex of the products dissociates irreversibly. A corresponding elimination of $\mathrm{H}$ from $\mathbf{a}$ is endothermic and not possible under the experimental conditions used.

Scheme 3

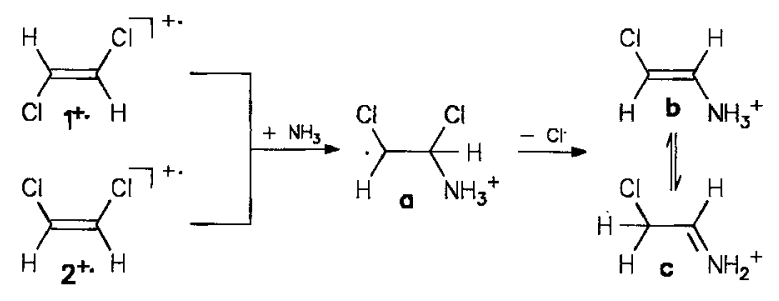

Scheme 4
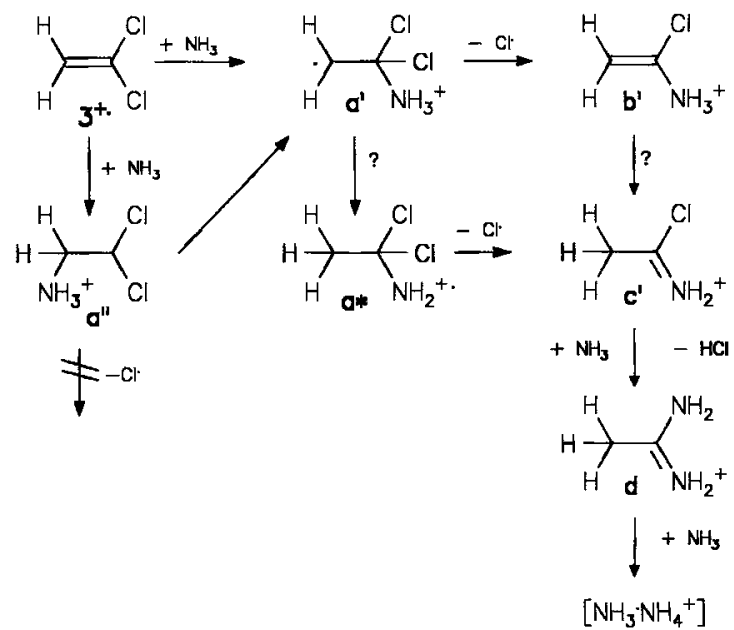

The addition of $\mathrm{NH}_{3}$ to $3^{+\cdot}$, however, may result in two different intermediate distonic ions $\mathbf{a}^{\prime}$ and $\mathbf{a}^{\prime \prime}$ (Scheme 4). The latter ion generated by the attachment of $\mathrm{NH}_{3}$ to the $\mathrm{CH}_{2}$ group of $3^{+\cdot}$ is distinctly more stable than its regio- 
isomer $\mathbf{a}^{\prime}$ (Tables 1 and 2), and the collision complex collapses preferentially to $\mathbf{a}^{\prime \prime}$. However, a further reaction of $\mathbf{a}^{\prime \prime}$ without any rearrangement is only possible by elimination of $\mathrm{HCl}$ and $\mathrm{H}$, but both reactions are not observed. Thus, $a^{\prime \prime}$ represents a "dead end" of the reaction and has to rearrange to $\mathbf{a}^{\prime}$ before the loss of $\mathrm{Cl}^{\circ}$. This rearrangement may occur by back dissociation of $\mathbf{a}^{\prime \prime}$ and reformation of $\mathbf{a}^{\prime}$, or by a 1,2-shift of the $\mathrm{NH}_{3}$ group in $\mathbf{a}^{\prime \prime}$. The rate of the reaction of $3^{+\cdot}$ with $\mathrm{NH}_{3}$ and the efficiency differ not significantly

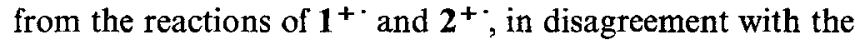
first possibility. In fact 1,2-shifts of $\mathrm{NH}_{3}$ groups have been observed in related distonic ammonium ions ${ }^{18)}$ and are probably very fast; thus this reaction path is the most likely one. the product ion $\mathbf{c}^{\prime}$ is a protonated imide chloride, and its further reaction with $\mathrm{NH}_{3}$ yielding the amidinium ion d $(m / z=59)$ is no surprise. This reaction is rather slow $\left(k_{\exp }=\right.$ $1.0 \cdot 10^{-7} \mathrm{~cm}^{3}$ molecule ${ }^{-1} \mathrm{~s}^{-1}$, efficiency $5.9 \%$ ), and the detailed course of the further reaction of $\mathbf{d}$ with $\mathrm{NH}_{3}$ is not yet known.

A comparison of the reactivities of the radical cation of the dichlorobenzenes and dichloroethenes towards $\mathrm{NH}_{3}$ reveals that the latter cations react much faster. The efficiencies for the reactions of the dichlorobenzenes vary between 15 (1,2-dichlorobenzene) and $0.4 \%$ (1,4-dichlorobenzene $)^{6}$, while the efficiencies of the isomeric dichloroethene radical cations have an almost constant value of $\geq 50 \%$. The ionneutral collision rate is approximated only by the ADO theory ${ }^{5)}$, and efficiencies $\geq 50 \%$ indicate that nearly every collision results in a chemical reaction. This would explain the absence of any structural effects of the dichlorethene radical cations on the reaction rate, in contrast to the behavior of the dichlorobenzene radical cations.

Application of the steady-state approximation to the kinetics of Schemes 3 and 4 shows that the experimental rate constant $k_{\text {exp }}$ of the total reaction depends on the rate constants of the individual reaction steps as shown by equation $(1)^{9)}$.

$$
\begin{aligned}
& k_{\exp }=\frac{k_{1} \times k_{2} \times k_{3}}{\left[\left(k_{-1}+k_{2}\right) \times\left(k_{-2}+k_{3}\right)\right]-k_{2} k_{-2}} \\
& k_{-1} \gg k_{2}: \quad k_{\exp }=\frac{k_{1}}{k_{-1}} \times k_{2} \times \frac{k_{3}}{k_{-2}+k_{3}}
\end{aligned}
$$

The assignment of the rate constants in equations (1a) and $(1 \mathrm{~b})$ to the reaction steps can be seen from Scheme 1; $k_{1}$ and $k_{-1}$ correspond to the collision rate and the rate of the back dissociation of the collision complex which does not vary much as long as reactions of the same neutral species are compared; $k_{2}$ and $k_{-2}$ are the rate constants of the addition step and the retro addition, respectively, within the collision complex, while $k_{3}$ is the rate constant of the irreversible dissociation to the products by loss of $\mathrm{X}$. The reactions of the radical cations of the halogenated benzenes are determined by $k_{2}$. This reaction step is exothermic by ca. $60 \mathrm{~kJ} / \mathrm{mol}$ but slow because of a large activation energy barrier ${ }^{6}$. Since $k_{-1} \gg k_{2}$, as shown by the low efficiencies, equation (1 a) can be simplified to equation ( $1 \mathrm{~b}$ ). Using the Shaik-Pross model of polar reactions ${ }^{10)}$, we can show that the activation barrier of the addition arises inter alia by an electron shift from the nucleophile to the radical cation during the reaction. This is most easily envisaged by the migration of the positive charge residing at the benzene radical cation in the initial state and being localized at the ammonium group in the products. As a consequence, the activation energy of the addition step depends on the difference $(\triangle I E)$ between the $I E$ value of the nucleophile and the $R E$ value of the radical cation (which can be approximated for a qualitative discussion by the $I E$ value of the corresponding neutral species). The important effect of $\Delta I E$ on the reaction between an unsaturated radical cation and a nucleophile is due to the fact that no reaction is observed if $\Delta I E$ exceeds ca. $2 \mathrm{eV}^{19)}$. The addition step of the reaction between the dichloroethene radical cations and $\mathrm{NH}_{3}$ (Schemes 3 and 4) is exothermic by $130-160 \mathrm{~kJ} / \mathrm{mol}$, distinctly more than in the case of the benzene radical cations. Furthermore, with $I E\left(\mathrm{NH}_{3}\right)=10.16 \mathrm{eV}^{14)}, I E(\mathbf{1})=9.65 \mathrm{eV}^{14)}, I E(\mathbf{2})=9.66$ $\mathrm{eV}^{14)}$, and $I E(3)=9.79 \mathrm{eV}^{14)}$ a $\Delta I E$ value of only $0.4-0.5$ $\mathrm{eV}$ is obtained. Both effects reduce the activation energy of the addition of $\mathrm{NH}_{3}$ to the olefine radical cations resulting in an increase of $k_{2}$. Hence, the addition step is not ratedetermining any more, and $k_{\exp }$ depends also on the other rate constants of equation (1a) and will approach the collision limit if $k_{2}>k_{-1}$ and $k_{3}>k_{-2}$, as observed experimentally.

\section{B) Reactions of Dichloro- and Dibromethenes with Radical Cations of Methylamine and Dimethylamine}

The $I E$ values of methylamine $\left(8.97 \mathrm{eV}^{14)}\right)$ and dimethylamine $\left(8.23 \mathrm{eV}^{14)}\right)$ are below those of the dichloroethenes (1: 9.65 $\mathrm{eV}^{14)} ; 2$ : $\left.9.66 \mathrm{eV}^{14)} ; 3: 9.79 \mathrm{eV}^{14)}\right)$ and $(E)$-1,2-dibromoethene (4: $\left.9.51 \mathrm{eV}^{14}\right)$ and (Z)-1,2-dibromoethene (5: 9.63 $\left.\mathrm{eV}^{14}\right)$. Hence, the only reaction between these dihaloethene radical cations and the neutral amines in the gas phase is a fast charge exchange yielding the amine radical cations and subsequently the ammonium ions. However, if $\mathrm{CH}_{3} \mathrm{NH}_{2}^{+}$. and $\left(\mathrm{CH}_{3}\right)_{2} \mathrm{NH}^{+}$, respectively, are generated in the external ion source and are treated after the transfer to the ICR cell with neutral 1, 2, 4 and 5 at a pressure of ca. $10^{-7} \mathrm{mbar}$, again the substitution of a halogen is observed. This sub-

Scheme 5
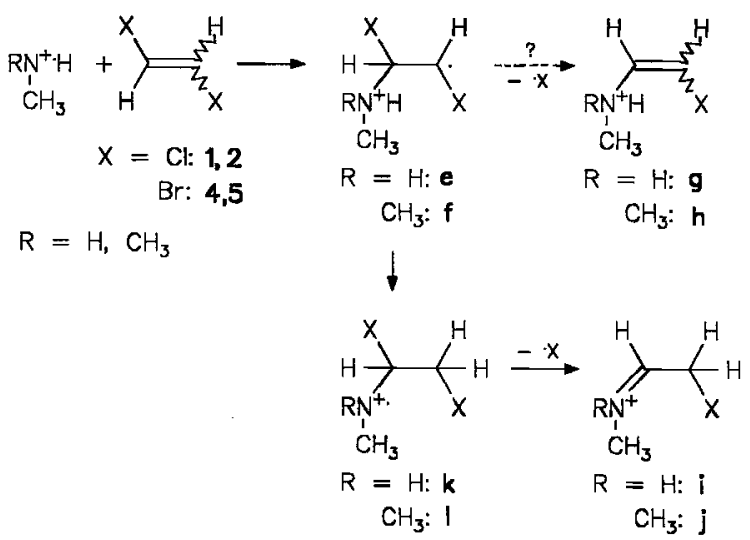

Chem. Ber. 124 (1991) 2349-2356 
stitution reaction is most easily portrayed by the additionelimination mechanism shown in Scheme 5. Note that this is not the addition of a nucleophile to an unsuturated radical cation, but the addition of an (electrophilic?) amine radical cation to a neutral alkene. This process resembles the reactions of amine radical cations with aromatic compounds in solution ${ }^{20)}$.

The Shaik-Pross model of polar reactions ${ }^{10)}$ predicts that in this case the critical electronic rearrangement during the reaction does not correspond to an electron shift but to an electron pairing between the radical cation and the neutral component. This is visualized in Scheme 5 by the fact that the positive charge stays at the nitrogen atom throughout the reaction. In contrast to the activation energy of the addition of a nucleophile to an unsaturated radical cation, that of the addition of an amine radical cation to an alkene should be rather small and should not depend very strongly on the $\Delta I E$ values of the reactants. Thus, the reaction is determined by the steps following the addition, i. e. the elimination of $\mathrm{X}$, and by the enthalpy of the total reaction.

The rate constants $k_{\text {exp }}$ for the substitution of neutral haloethenes by $\mathrm{CH}_{3} \mathrm{NH}_{2}^{+\cdot}$ and $\left(\mathrm{CH}_{3}\right)_{2} \mathrm{NH}^{+\cdot}$ are listed in Table 3 together with relevant thermochemical data. The heats of formation of the species involved were calculated again by MNDO and are listed in Table 4. Apparently, the expectations of a fast substitution reaction and the dominating influence of the dissociation step are born out by the high efficiencies of 41 and $35 \%$ for the reaction of 1 and 2, respectively, with $\mathrm{CH}_{3} \mathrm{NH}_{2}^{+}$, and a further increase of the efficiencies for the reactions of the dibromoethenes $\mathbf{4}$ and $\mathbf{5}$. However, the reactions of the amine radical cations are cer-

Table 3. Rate constants $k$, efficiencies (eff.), and energetics ${ }^{\text {a) }}$ of the reactions of amine ${ }^{+}$ions with dichloro- and dibromoethenes

$$
1-5
$$

\begin{tabular}{|c|c|c|c|c|c|}
\hline Compd. & $\mathrm{k}^{\mathrm{b})}$ & eff.c) & $\begin{array}{c}\Delta \mathrm{H}_{\mathrm{x}} \\
{\left[\mathrm{kJ} \mathrm{mol}^{-1}\right]}\end{array}$ & $\underset{\left[\mathrm{kJ} \mathrm{mol}^{-1}\right]}{\Delta \mathrm{H}_{\mathrm{r}}}$ & $\underset{\left[\mathrm{kJ} \mathrm{mol}^{-1}\right]}{\left.\Delta \mathrm{H}_{\mathrm{add}}\right]}$ \\
\hline & \multicolumn{2}{|c|}{$\begin{array}{l}\text { Reactions with } \\
\mathrm{CH}_{3} \mathrm{NH}_{2}^{+}{ }^{+}\end{array}$} & $\begin{array}{c}\text { Formation } \\
\text { of } g / g^{\prime}\end{array}$ & $\begin{array}{c}\text { Formation } \\
\text { of } \mathbf{i} / \mathbf{i} \text { ' }\end{array}$ & $\begin{array}{c}\text { Formation } \\
\text { of } \mathbf{e} / \mathbf{m}\end{array}$ \\
\hline 1 & $5.6 \cdot 10^{-10}$ & $41 \%$ & +6 & -44 & -101 \\
\hline 2 & $6.7 \cdot 10^{-10}$ & $35 \%$ & +2 & -48 & -105 \\
\hline 3 & $1.4 \cdot 10^{-10 d)}$ & $8.1 \%$ d) & +5 & -56 & $-68^{f}$ \\
\hline 4 & $9.9 \cdot 10^{-10}$ & $68 \%$ & & & \\
\hline \multirow[t]{2}{*}{5} & $\left.10.6 \cdot 10^{-10} \mathrm{e}\right)$ & $59 \% \%^{\mathrm{e})}$ & & & \\
\hline & \multicolumn{2}{|c|}{$\begin{array}{l}\text { Reactions with } \\
\left(\mathrm{CH}_{3}\right)_{2} \mathrm{NH}^{+}\end{array}$} & $\begin{array}{c}\text { Formation } \\
\text { of } \mathbf{h} / \mathbf{h} \text { ' }\end{array}$ & $\begin{array}{c}\text { Formation } \\
\text { of } \mathbf{j} / \mathbf{j}\end{array}$ & $\begin{array}{c}\text { Formation } \\
\text { of } \mathbf{f} / \mathbf{n} \\
\end{array}$ \\
\hline 1 & $8.5 \cdot 10^{-12}$ & $0.72 \%$ & +64 & +8 & -32 \\
\hline 2 & $5.0 \cdot 10^{-12}$ & $0.30 \%$ & +60 & +4 & -36 \\
\hline 3 & \multicolumn{2}{|c|}{ no reaction } & +67 & -2 & $+6^{g)}$ \\
\hline 4 & $8.8 \cdot 10^{-11}$ & $7.1 \%$ & & & \\
\hline 5 & $\left.11.2 \cdot 10^{-11} \mathrm{e}\right)$ & $7.3 \%$ e) & & & \\
\hline
\end{tabular}

${ }^{a 1}$ Heats of reaction/formation $\Delta H_{\mathrm{r}} / \Delta H_{\mathrm{f}}$ according to MNDO calculations. - b) In units $\left[\mathrm{cm}^{3}\right.$ molecule $\left.{ }^{-1} \mathrm{~s}^{-1}\right]$. - Collision rate according to the ADO theory. - d) Reaction rate and efficiency for substitution reaction only. - ${ }^{\text {e) }}$ Reaction rate estimated for pure $(Z)$ isomer from the mixture of isomers. - if Formation of $p$ : $\Delta H_{\text {add }}=-140 \mathrm{~kJ} \mathrm{~mol}^{-1} \cdot{ }^{\mathrm{g})}$ Formation of q: $\Delta H_{\mathrm{add}}=-74 \mathrm{~kJ}$ $\mathrm{mol}^{-1}$. tainly more complicated than assumed by a simple additionelimination mechanism. This is indicated by the very slow reaction of the dihaloethenes with $\left(\mathrm{CH}_{3}\right)_{2} \mathrm{NH}^{+^{+}}$(Table 3$)$ and the unique behavior of 3 to be discussed below. The MNDO calculations of the $\Delta H_{\mathrm{f}}$ values of the reactants and the reaction products (Table 4) reveal that a formation of protonated enamines $\mathbf{g}$ and $\mathbf{h}$ from $\mathbf{1}$ and 2 , respectively, is slightly endothermic for the reaction of $\mathrm{CH}_{3} \mathrm{NH}_{2}^{+\cdot}$ and strongly endothermic for the reaction of $\left(\mathrm{CH}_{3}\right)_{2} \mathrm{NH}^{+}$. In the latter case the endothermicity of $60-65 \mathrm{~kJ} / \mathrm{mol}$ is clearly outside the limits of error of the MNDO calculations, and a reaction yielding directly the protonated enamines $\mathbf{g}$ and $\mathbf{h}$ is not possible at the thermal energy of the reactants. Thus, the reaction products have to be the immonium ions $\mathbf{i}$ and $\mathbf{j}$ to make the subsitution exothermic $\left(\mathrm{CH}_{3} \mathrm{NH}_{2}^{+}\right)$or nearly thermoneutral $\left[\left(\mathrm{CH}_{3}\right)_{2} \mathrm{NH}^{+}\right]$, and these products have to be formed directly by the dissociation of $\mathrm{Cl}^{\circ}$ and $\mathrm{Br}$, respectively, from an appropriate reaction intermediate. In this case the steep decrease of the efficiencies between the reactions of $\mathrm{CH}_{3} \mathrm{NH}_{2}^{+{ }^{*}}$ and $\left(\mathrm{CH}_{3}\right)_{2} \mathrm{NH}^{+\cdot}$ with the dihaloalkenes (Table 3) reflects the transition from an exothermic to a nearly thermoneutral ion-molecule reaction.

Table 4. Experimental and calculated heats of formation $\Delta H_{\mathrm{f}}$ of dichloroethenes $1-3$ and reaction products with methyl- and dimethylamine radical cations, respectively ${ }^{\text {a) }}$

\begin{tabular}{|c|c|c|}
\hline Compound & $\begin{array}{l}\text { MNDO Calculations } \\
\Delta \mathrm{H}_{\mathrm{f}}\left[\mathrm{kJ} \mathrm{mol}^{-1}\right]\end{array}$ & $\begin{array}{r}\text { Experimental }{ }^{14} \\
\Delta \mathrm{H}_{\mathrm{f}}\left[\mathrm{kJ} \mathrm{mol}^{-1}\right]\end{array}$ \\
\hline 1 & -16 & +4 \\
\hline 2 & -12 & +4 \\
\hline 3 & -1 & +2 \\
\hline $\mathrm{CH}_{3} \mathrm{NH}_{2}^{+\cdot}$ & 884 & 841 \\
\hline$\left(\mathrm{CH}_{3}\right)_{2} \mathrm{NH}^{+\cdot}$ & 845 & 774 \\
\hline e & 767 & \\
\hline f & 797 & \\
\hline $\mathbf{g}$ & 753 & \\
\hline$g^{\prime}$ & 767 & \\
\hline h & 772 & \\
\hline$h^{2}$ & 790 & \\
\hline i & 703 & \\
\hline i' & 706 & \\
\hline $\mathbf{j}$ & 716 & \\
\hline $\mathbf{j}^{\prime}$ & 721 & \\
\hline $\mathbf{k}$ & 810 & \\
\hline 1 & 798 & \\
\hline $\mathbf{m}$ & 815 & \\
\hline $\mathbf{p}$ & 743 & \\
\hline $\mathbf{r}$ & 813 & \\
\hline
\end{tabular}

a) For structure of ions see Schemes 5 and 6 .

As a consequence of this thermochemical situation, the distonic ions $\mathbf{e}$ and $\mathbf{f}$ (Scheme 5) formed by the addition step have to rearrange by hydrogen shifts to the isomeric ions $\mathbf{k}$ and $\mathbf{l}$ which are not (l) or only $40 \mathrm{~kJ} / \mathrm{mol}$ (k) higher in energy than $e$ and $f$, but better prepared for a direct loss of $X$. The detailed course of the hydrogen rearrangements is not 
known because of the absence of many experiments with deuterated derivatives, but excessive hydrogen rearrangements have been reported for related distonic ammonium ions ${ }^{18)}$. The addition of the amine radical cations to the alkenes is exothermic for all cases where a reaction takes place (Table 4), and the ions e and $\mathbf{f}$ are formed as highly chemically activated species which can use the excess energy for fast hydrogen shifts giving rise eventually to the "conventional" amine molecular ions $\mathbf{k}$ and $\mathbf{I}$.

According to this mechanism, the low reactivity of $\left(\mathrm{CH}_{3}\right)_{2} \mathrm{NH}^{+\cdot}$ towards haloethenes is caused by a more or less thermoneutral reaction. This can be traced to the high stability of this amine radical cation which is also seen from the low IE value of $\left(\mathrm{CH}_{3}\right)_{2} \mathrm{NH}\left(8.23 \mathrm{eV}^{14)}\right)$. It is interesting to note that by this thermochemical effect of the $R E$ (or $I E$ ) values of different amine radical cations still have an influence on the reactivity of the substitution reactions although no effect on the rate of the intermediate addition step is expected. It is obvious that this thermochemical effect is a general phenomenon for this type of substitution reaction of neutral alkenes, and that the reactivity of radical cations with a small value for $R E$ (or $I E$ of the corresponding neutral species) will be low.

The 1,1-dichlorethene 3 exhibits a different reactivity towards the amine radical cations (Scheme 6). No reaction is observed with $\left(\mathrm{CH}_{3}\right)_{2} \mathrm{NH}^{+\cdot}$ although the substitution would be slightly exothermic by assuming an immonium product ion. Even more puzzling is the observation of a low efficiency of only $8.1 \%$ for a substitution by $\mathrm{CH}_{3} \mathrm{NH}_{2}^{+\cdot}$ although this reaction would be at least as exothermic as in the case of 1 and 2. Instead, the main reaction product $(61 \%)$ is an ion $\mathrm{CH}_{2}=\mathrm{NH}_{2}^{+}$arising formally by a hydrogen abstraction from $\mathrm{CH}_{3} \mathrm{NH}_{2}^{+\cdot}$ by the neutral species 3. Clearly, this peculiar behavior of 3 is not a thermochemical effect but must be due to a different structural situation in the reaction intermediates. In contrast to the reactions of $\mathbf{1}$ and $\mathbf{2}$ (and also of $\mathbf{4}$ and 5 ) the addition of the amine radical cations to

Scheme 6

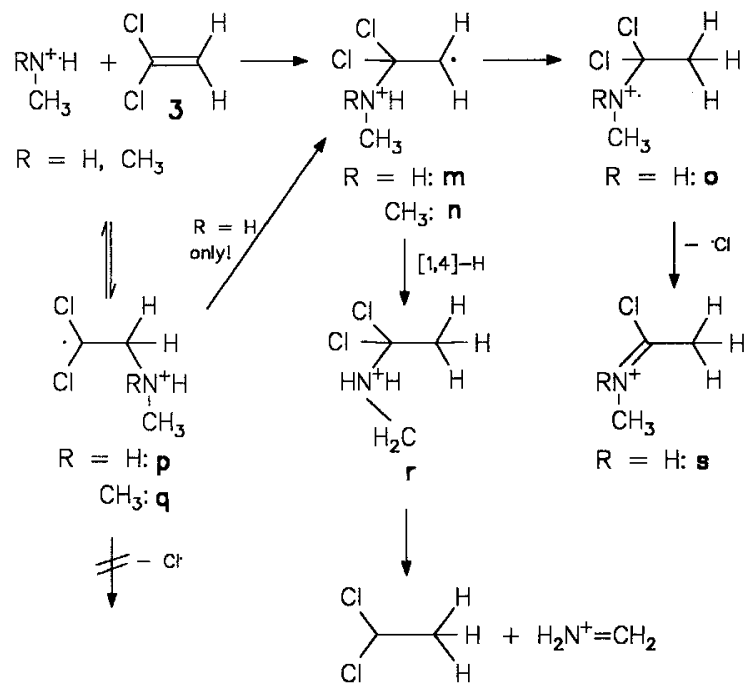

3 gives rise to the formation of different distonic ions $\mathbf{m}$ (n) and $\mathbf{p}(\mathbf{q})$, depending on the site of attack (Scheme 6). Addition of the amine radical cation to the unsubstituted carbon-atom of 3 is clearly favored because of the stability of the resulting 1,1-dichloroethyl radical group. It has already been mentioned that $\beta$-distonic ammonium ions interconvert by a 1,2 -shift of the amine group ${ }^{18)}$. However, the transition state of the interconversion resembles a tight complex of an alkene radical cation and a neutral amine ${ }^{21)}$. While this electronic configuration is energetically favorable for the distonic ammonium ions $\mathbf{a}^{\prime}$ and $\mathbf{a}^{\prime \prime}$ (Scheme 4 ) arising by the addition of $\mathrm{NH}_{3}$, it is a highly excited state in the case of $\mathbf{p}$ and $\mathbf{q}$ because of the much lower $I E$ values of methylamine and in particular dimethylamine. Consequently, the interconversion of $\mathbf{p}$ and $\mathbf{m}$ (addition of $\mathrm{CH}_{3} \mathrm{NH}_{2}^{+}$) is expected to be slow, and that of $\mathbf{q}$ and $\mathbf{n}$ [addition of $\left(\mathrm{CH}_{3}\right)_{2} \mathrm{NH}^{+}{ }^{+}$] is energetically not possible. Thus, most (or all) of the preferentially formed addition products $\mathbf{p}$ and $\mathbf{q}$ which cannot dissociate by loss of $\mathrm{Cl}$; will instead dissociate back to the starting components. This explains the low efficiency of the exothermic substitution of 3 by $\mathrm{CH}_{3} \mathrm{NH}_{2}^{+\cdot}$ and the absence of the still slightly exothermic substitution by $\left(\mathrm{CH}_{3}\right)_{2} \mathrm{NH}^{+}$.

Another consequence of the geminal dichloro substitution is the generation of $\mathrm{CH}_{2}=\mathrm{NH}_{2}^{+}$from 3 and $\mathrm{CH}_{3} \mathrm{NH}_{2}^{+}$. It is very unlikely that this reaction corresponds to a direct hydrogen abstraction by the neutral 1,1-dichloroethene. However, inernal hydrogen abstractions are expected for distonic ions, and the $\beta$-distonic ion $\mathbf{m}$ slowly arising by isomerization of the initially formed $\mathbf{p}$ may rearrange to the $\alpha$-distonic ion $\mathbf{r}$ by an exothermic 1,4-hydrogen shift from the $N$-methyl group (Scheme 6). Related 1,4-hydrogen shifts in radical cations are well-known from mass-spectrometric fragmentations ${ }^{22)}$ and exhibit only moderate activation energies. The $\alpha$-distonic ion $\mathbf{r}$ easily fragments to the ion $\mathrm{CH}_{2}=\mathrm{NH}_{2}^{+}$and a stable 1,1-dichloroethyl radical. Since the isomerization of $\mathbf{p}$ to $\mathbf{m}$ is imperative for the formation of $\mathbf{r}$ and its further dissociation, an analogous formation of $\mathrm{CH}_{2}=\mathrm{NH}^{+} \mathrm{CH}_{3}$ is obstructed in the case of an addition of $\left(\mathrm{CH}_{3}\right)_{2} \mathrm{NH}^{+\cdot}$ to 3 because of the absence of the analogous isomerization of $\mathbf{q}$ to $\mathbf{n}$.

\section{Conclusion}

The results of this FT-ICR study of the reaction of halogenated ethene radical cations with $\mathrm{NH}_{3}$ and of amine radical cations with neutral haloethenes demonstrate again the possibilities of the FT-ICR technique for the investigation of the mechanisms of elementary reactions of organic ions. In the cases studied it is clear that both the substitution reactions of ethene radical cations with $\mathrm{NH}_{3}$ and of the amine radical cations with ethenes proceed by an additionelimination mechanism. However, in contrast to the analogous substitution reaction of halogenated benzene radical cations with $\mathrm{NH}_{3}$ the addition step is not rate-determining. Thus, the $\beta$-distonic ammonium ions generated by the exothermic step are important intermediates determining the efficiency and the further course of the reaction. The initially formed $\beta$-distonic ion rearranges by a 1,2-shift of the $\mathrm{NH}_{3}$ 
or amino group as well as by hydrogen migration before loss of a halogen substituent occurs. Obviously, these rearrangement steps strongly depend on the detailed structure of the intermediate distonic ions and in particular on the nature of the amine group. Thus, the substitution reactions of dihaloethenes by $\mathrm{NH}_{3}$ and amines via radical cations exhibit an interesting and rich chemistry.

The FT-ICR spectrometer used is a gift of the Deutsche Forschungsgemeinschaft, and we thank the Deutsche Forschungsgemeinschaft for the financial assistance. Additional assistance by the Fonds der Chemischen Industrie is gratefully acknowledged. D. T. thanks the Studienstiftung des Deutschen Volkes for a Stipendium during this work.

\section{Experimental}

The FR-ICR measurements were performed with a Spectrospin CMS 47X FT-ICR instrument ${ }^{23)}$ equipped with a superconducting magnet (4.7 T), an ASPECT 3000 computer ( $24 \mathrm{bits} / 128 \mathrm{k}$-word), a cylindrical cell with a diameter of $6 \mathrm{~cm}$ and length of $6 \mathrm{~cm}$ an an external ion source ${ }^{24)}$.

Ions were generated by electron impact $(18-25 \mathrm{eV})$ from the dihaloethenes and the methyl- and dimethylamines, respectively, and transferred to the ICR cell. The trapping voltages on the front and back trapping plates were $1 \mathrm{~V}$, the excitation- and detectionplate DC voltages were $0 \pm 0.1 \mathrm{~V}$. Selection of the radical cations was achieved by broad-band (frequency sweep) ejection of fragment ions with $m / z>50$. The excitation voltage was attenuated by an attenuator of 6 , corresponding to $88 \mathrm{~V}_{\mathrm{p}-\mathrm{p} \text {. All ions with } m / z<50}$ and the isotopomers of the radical cations containing ${ }^{13} \mathrm{C},{ }^{37} \mathrm{Cl}$, and ${ }^{81} \mathrm{Br}$ isotopes were ejected by "single shots" (fixed-frequency if pul-

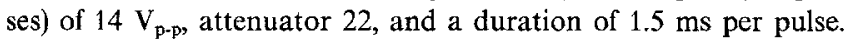
The total ejection process was finished within $15-20 \mathrm{~ms}$.

Ammonia (99.8\%; Merck) and the dihaloethenes, respectively, as reactant gases were introduced continuously by a leak valve, the calibrated pressure ranged from $3 \cdot 10^{-8}$ to $6 \cdot 10^{-7}$ mbar. The ionization gauge was connected close to the diffusion pump of the ICR cell and the pressure was calibrated by rate measurements of the reactions $\mathrm{CH}_{4}^{+\cdot}+\mathrm{CH}_{4}\left(k=1.5 \cdot 10^{-9} \mathrm{~cm}^{3} \mathrm{~s}^{-1}\right)^{25 y}$ and $\mathrm{NH}_{3}^{+\cdot}+\mathrm{NH}_{3}$ $\left(k=2.2 \cdot 10^{-9} \mathrm{~cm}^{3} \mathrm{~s}^{-1}\right)^{13}$. The sensitivity o the ionization gauge to the dihaloethenes was evaluated by a standard literature procedure ${ }^{26)}$ taking $\mathrm{NH}_{3}$ as the reference. The FT-ICR spectra were obtained with $32 \mathrm{~K}$ data for ca. 20 different reaction times up to $95 \%$ conversion of the reacting radical cations and at least two different $\mathrm{NH}_{3}$ pressures, respectively. After exponential multiplication of the time-domain signal and Fourier transformation, the ion intensities of the magnitude spectra were normalized with respect to the sum of ions formed after the corresponding reaction time. A pseudo-first-order-reaction kinetics was obtained from the exponential decaying signal of the reacting radical cations. To ensure the correct measurement of the true ion abundances the variation of the sum of the absolute ion intensities with reaction time was examined and compared with the variation of the intensity of trapped unreactive ions at the corresponding delay times ("trapping characteristics"). This method allows a correction of erroneous ionabundance measurements and is described in detail in ref. ${ }^{9}$. If more than two ions are involved in the reaction in higher abundances, i.e. more than one product ion is formed, the method is not reliable, however. Therefore, the determination of the branching ratio in competitive substitutions of two substituents may be less accurate. In these cases special care was taken to avoid "picket-fence" errors $^{27)}$ by suitable exponential multiplication. The ions isolated in the ICR cell had more or less excess kinetic energy. A "cooling" of these ions was achieved by pulsing shortly (opening time of the valve $15 \mathrm{~ms}$ ) argon into the ICR cell prior to the reaction. The reacting ions were selected by the ejection process described above and "cooled" by collision with argon. After a delay time of $500 \mathrm{~ms}$ to remove the argon from the cell, the fragment ions formed during that time were ejected by "single shots" $\left(14 \mathrm{~V}_{\mathrm{p}-\mathrm{p}}, 1.5 \mathrm{~ms}\right)$. This method is described in detail in ref. ${ }^{6}$.

All compounds were obtained commercially, the 1,2-dihaloethenes were separated into the $(E)$ and $(Z)$ isomers by distillation, and their purity was determined by gas chromatography and ${ }^{1} \mathrm{H}-\mathrm{NMR}$ spectroscopy. (E)-1,2-dichloroethene (1) (bp. $47-48^{\circ} \mathrm{C}$, purity 99\%), (Z)-1,2-dichloroethene (2) (bp. 59-60 ${ }^{\circ} \mathrm{C}$, purity $98 \%$ ), and (E)-1,2-dibromoethene (4) (bp. $103-104^{\circ} \mathrm{C}$, purity $98 \%$ ) could be obtained by destillation. (Z)-1,2-dibromoethene (5) could not be obtained by distillation and was used in a 1:1 mixture with 4. 1,1Dichloroethene (3) was distilled directly before use and was $>99 \%$ pure according to gas chromatography.

\section{CAS Registry Numbers}

$\mathbf{1}^{+}:$: 73245-64-4/2 $\mathbf{2}^{+\bullet}: 73245-65-5 / 3^{+\bullet}:$ 135004-40-9 / a: 13500441-0/a': 135004-42-1/a": 135004-43-2 / b: 135004-44-3 / $\mathbf{b}^{\prime}$ : 135004-45-4 / c: $135004-46-5 / \mathbf{c}^{\prime}: 135004-47-6$ /e: $135004-48-7$ /f: 135004-49-8 /g: 135004-50-1/g': 135004-51-2 / h: 135004-52-3 / $\mathbf{h}^{\prime}: 135004-53-4$ /i: $135004-54-5 / \mathbf{j}: 135004-55-6 / \mathbf{j}^{\prime}: 58896-53-0$ / k: 135004-56-7 / l: 135004-57-8 / m: 135004-58-9 / n: 135004-61-4 / p: 135004-59-0 / q: 135004-62-5 / r: 135004-60-3 / s: 135041-39-3/ $(Z)-(\mathrm{Cl}) \mathrm{CH}=\mathrm{CH}(\mathrm{Cl}): 156-59-2 /(E)-(\mathrm{Cl}) \mathrm{CH}=\mathrm{CH}(\mathrm{Cl}): 156-60-5 /$ $\mathrm{CH}_{2}=\mathrm{CCl}_{2}:$ 75-35-4 / $(Z)-(\mathrm{Br}) \mathrm{CH}=\mathrm{CH}(\mathrm{Br}): 590-11-4 /(E)-(\mathrm{Br})-$ $\mathrm{CH}=\mathrm{CH}(\mathrm{Br}): 590-12-5 / \mathrm{NH}_{3}: 7664-41-7 / \mathrm{MeNH}_{2}^{+}:$34516-31-9/ $\mathrm{MeNH}^{+\bullet}: 34536-36-2$

\& Dedicated to Professor Michael Hanack on the occasion of his 60th birthday.

1) 1a) M. Hanack, Angew. Chem. 90 (1978) 346; Angew. Chem. Int. Ed. Engl. 17 (1978) 333. - ${ }^{16)}$ M. Hanack, Acc. Chem. Res. 3 (1970) 209.

2) za) $\mathrm{K}$. Yoshiba, Electrooxidation in Organic Chemistry, Whiley and Sons, New York 1984. - 2b) Photoinduced Electron Transfer (M. A. Fox, M. Channon, Eds.), Elsevier, Amsterdam 1988.

3) 3a) E. E. Ferguson, F. C. Fehsenfeld, A. L. Schmeltekopf, Adv. At. Mol. Phys. 5 (1969) 1. - ${ }^{36)}$ N. G. Adams, D. Smith, Int. J. Mass Spectrom. Ion Phys. 21 (1976) 349.

${ }_{4)}^{4}{ }_{4 a)}$ M. B. Comisarow, Adv. Mass Spectrom. 8 (1980) 1698. - ${ }^{4 b)}$ A. G. Marshall, Acc. Chem. Res. 18 (1985) 316. - ${ }^{4 c)}$ N. M. M. Nibbering, Adv. Mass Spectrom. 10 (1985) 417. - ${ }^{4 d)}$ D. A. Laude, Jr., C. L. Johlmann, R. S. Brown, D. A. Weil, C. L. Wilkins, Mass Spectrom. Rev. 5 (1986) 107.

5) T. Su, M. T. Bowers, Int. J. Mass Spectrom. Ion Phys. 12 (1973) 347.

6) D. Thölmann, H.-F. Grützmacher, J. Am. Chem. Soc. 113 (1991) 3281 .

7) 7a) J. van Thuijl, W. C. M. M. Luijten, W. Onkenhout, J. Chem. Soc., Chem. Commun. 1980, 106. - 7b) W. C. M. M. Luijten, W. Onkenhout, J. van Thuijl, Org. Mass Spectrom. 15 (1980) 329.

8) 8a) D. Thölmann, R. Wolf, H.-F. Grützmacher, Adv. Mass Spectrom. 11 A (1989) 556. - ${ }^{8 b)}$ D. Thölmann, H.-F. Grützmacher, Org. Mass Spectrom. 24 (1989) 439.

9) D. Thölmann, H.-F. Grützmacher, Chem. Phys. Lett. 163 (1989) 225.

10) 10a) S. S. Shaik, J. Am. Chem. Soc. 103 (1981) 3692. - 10b) A Pross, S. S. Shaik, Acc. Chem. Res. 16 (1983) 363. - ${ }^{10 c)}$ S. S. Shaik, Prog. Phys. Org. Chem. 15 (1985) 197. - 10d) D. Cohen, R. Bar, S. S. Shaik, J. Am. Chem. Soc. 108 (1986) 231. - ${ }^{10 \mathrm{e})}$ A. Pross, J. Am. Chem. Soc. 108 (1986) 3537. - ${ }^{100}$ S. S. Shaik, A. Pross, J. Am. Chem. Soc. 111 (1989) 4306. - $\left.{ }^{10 g}\right)$ S. S. Shaik, Acta 
Chem. Scand. 44 (1990) 205, - ${ }^{10 h)}$ S. S. Shaik, E. Canadell, J. Am. Chem. Soc. $112(1990) 1446$.

11) 11a) B. Brutschy, J. Phys. Chem. 94 (1990) 8637. - 11b) J. Eggert C. Janes, B. Wassermann, B. Brutschy, H. Baumgärtel, Ber. Bunsenges. Phys. Chem. 94 (1990) 1282.

12) 12a) T. Drewello, N. Heinrich, W. P. M. Maas, N. M. M. Nibbering, T. Weiske, H. Schwarz, J. Am. Chem. Soc. 109 (1987) 4810. - ${ }^{12 b)}$ B. Reitstöen, F. Norrsel, V. D. Parker, J. Am. Chem. Soc. 111 (1989) 8463.

13) N. G. Adams, D. Smith. J. F. Paulson, J. Chem. Phys. 72 (1980) 288.

14) S. G. Lias, J. F, Liebmann, J. L. Holmes, R. D. Levin, W. G. Mallard, J. Phys. Chem. Ref. Data 17 (1988), Suppl. 1.

15) 15a) M. J. S. Dewar, W. J. Thiel, J. Am. Chem. Soc. 99 (1977) 4899. - ${ }^{15 b)}$ M. J. S. Dewar, W. J. Thiel, J. Am. Chem. Soc. 99 (1977) 4907.

16) G. Frenking, W. Koch, J. Mol. Struct. 110 (1984) 49.

17) 17a) L. Radom, W. J. Bouma, R. H. Nobes, B. F. Yates, Pure Appl. Chem. 56 (1984) 1831. - ${ }^{17 b)}$ S. Hammerum, Mass. Spectrom. Rev. 7 (1988) 123.
18) 18a) S. Hammerum, D. Kuck, P. J. Derrick, Tetrahedron Lett. 25 (1984) 893. - ${ }^{18 b)}$ S. Hammerum, S. Ingemann, N. M. M. Nibbering, Org. Mass Spectrom. 20 (1985) 314 _ ${ }^{18 c)}$ T. Björnholm, S. Hammerum, D. Kuck, Adv. Mass Spectrom. 10 (1985) 787.

19) D. Thölmann and H.-F. Grützmacher, unpublished results.

20) 20a) F. Kinisci, Top. Curr. Chem. 62 (1976) 1. - 20b) G. Sosnovsky, D. J. Rawlinson, Adv. Free Radical Chem. 4 (1972) 203.

21) B. B. Yates, L. Radom, Org. Mass Spectrom. 22 (1987) 430

22) 22a) D. A. McAdoo, C. E. Hudson, Org. Mass Spectrom. 18 (1983) 466. - ${ }^{22 b)}$ D. A. McAdoo, Org. Mass Spectrom. 23 (1988) 350.

${ }^{23)}$ M. Allemann, Hp. Kellerhals, K. P. Wanczek, Int. J. Mass Spectrom. Ion Phys. 46 (1983) 139.

24) P. Kofel, M. Allemann, Hp. Kellerhals, K. P. Wanczek, Int. J. Mass Spectrom. Ion Processes 65 (1985) 97.

${ }^{25)}$ D. Smith, N. G. Adams, Int. J. Mass Spectrom. Ion Phys. 23 (1977) 123.

26) J. E. Bartmess, R. M. Georgiadis, Vacuum 33 (1983) 149.

27) A. J. Noest, C. W. Kort, Comput. Chem. 6 (1982) 115.

[150/91] 